\title{
The impact and collateral damage of COVID-19 on prostate MRI and guided biopsy operations: Society of Abdominal Radiology Prostate Cancer Disease-Focused Panel survey analysis
}

\author{
Devaki Shilpa S. Surasi ${ }^{1,7}$. Xuemei Wang ${ }^{2} \cdot$ Tharakeswara K. Bathala $^{1,7} \cdot$ Hyunsoo Hwang ${ }^{2}$. Sandeep Arora ${ }^{3,7}$. \\ Antonio C. Westphalen ${ }^{4,7} \cdot$ Silvia D. Chang ${ }^{5,7} \cdot$ Baris Turkbey $^{6,7}$
}

Received: 18 January 2021 / Revised: 3 April 2021 / Accepted: 9 April 2021 / Published online: 27 April 2021

(c) The Author(s), under exclusive licence to Springer Science+Business Media, LLC, part of Springer Nature 2021

\begin{abstract}
The Coronavirus disease 2019 (COVID-19) pandemic has significantly affected health care systems throughout the world. A Qualtrics survey was targeted for radiologists around the world to study its effect on the operations of prostate MRI studies and biopsies. Descriptive statistics were reported. A total of 60 complete responses from five continents were included in the analysis. $70 \%$ of the responses were from academic institutions. Among all participants, the median (range) number of prostate MRI was $20(0,135)$ per week before the COVID-19 pandemic versus $10(0,30)$ during the lockdown period; the median (range) number of prostate biopsies was $4.5(0,60)$ per week before the COVID-19 versus $0(0,12)$ during the lockdown period. Among the $30 \%$ who used bowel preparation for their patients prior to MRI routinely, $11 \%$ stopped the bowel preparation due to the pandemic. $47 \%$ reported that their radiology departments faced staff disruptions, while $68 \%$ reported changes in clinic schedules in other clinical departments, particularly urology, genitourinary medical oncology, and radiation oncology. Finally, COVID-19 pandemic was found to disrupt not only the clinical prostate MRI operations but also impacted prostate MRI/biopsy research in up to $50 \%$ of institutions. The impact of this collateral damage in delaying diagnosis and treatment of prostate cancer is yet to be explored.
\end{abstract}

Keywords MRI $\cdot$ COVID-19 $\cdot$ Pandemic $\cdot$ Collateral damage $\cdot$ Prostate cancer $\cdot$ Prostate biopsy

\section{Introduction}

Devaki Shilpa S. Surasi

dssurasi@mdanderson.org

1 Division of Diagnostic Imaging, The University of Texas MD Anderson Cancer Center, Houston, TX, USA

2 Department of Biostatistics, The University of Texas MD Anderson Cancer Center, Houston, TX, USA

3 Department of Radiology and Biomedical Imaging, Yale School of Medicine, New Haven, CT, USA

4 Departments of Radiology, Urology and Radiation Oncology, University of Washington, Seattle, WA, USA

5 Department of Radiology, Vancouver General Hospital, University of British Columbia, Vancouver, Canada

6 Department Molecular Imaging Branch, Center for Cancer Research, National Cancer Institute, National Institutes of Health, Bethesda, MD, USA

7 Society of Abdominal Radiology, 1061 E. Main Street, Suite 300, East Dundee, IL, USA
The pandemic caused by a novel coronavirus, severe acute respiratory syndrome coronavirus 2 (SARS CoV-2), was first identified in December 2019 and designated coronavirus disease 2019, or COVID-19 [1]. It has severely paralyzed the health care system and economy all around the world. There are 76,238,296 confirmed cases and 1,684,816 global deaths according to the COVID-19 dashboard by the Center for Systems Science and Engineering at Johns Hopkins University as of December 19, 2020 [2]. While COVID-19 directly affects the patients, families, and healthcare workers, it indirectly causes disruptions and delays in health care in multiple settings. There are case reports describing the delays in medical care and cancer diagnosis $[3,4]$. The healthcare system changes have also threatened the delivery of trauma and acute stroke care due to the diversion of resources [5, 6]. Besides, public health interventions like screening programs have also been impacted and hence there is a need to develop best practices to allow the screening programs to 
protect all the stakeholders [7]. To safely improve access to healthcare, most clinical practices have switched to telemedicine [8]. One of the potential areas of collateral damage includes prostate-related diagnostic imaging and interventions. Delayed diagnosis risks the progression of disease, which in turn may impact the long-term survival of patients. The primary objective of this online survey is to analyze the operational changes, including the volume of cases and departmental policy changes made during the initial few months of the COVID-19 pandemic.

\section{Material and methods}

This HIPAA-compliant prospective survey-based study received institutional review board approval from the research ethics committee at The University of Texas MD Anderson Cancer Center, Houston, United States. Answering "Yes" to the first question served as consent to participate in the study. The authors developed the study as an initiative of the Society of Abdominal Radiology Prostate Cancer Disease-Focused Panel (SAR PC DFP). The Qualtrics survey consisting of 30 questions, was distributed electronically to radiologists around the world. The source of the targeted radiologists consisted mainly of the membership of SAR PC DFP, which includes radiologists from both within and outside the United States. In total, the survey was e-mailed individually to 150 radiologists with a unique link which could not be forwarded to others. To increase participation, a survey link was also posted on the official Twitter account of SAR PC DFP (https://twitter.com/SAR_ ProstateDFP). The links were kept active during various time-points from July to August 2020, and the survey was closed after a month. The questionnaire included practice type, location, dates and duration of lockdown, number of cases before, during, and after the lockdown, protocols and COVID-19 specific questions (Appendix). The term "lockdown" refers to the period of mass quarantine or stay at home orders when the outpatient and non-emergent studies were cancelled. No patient health information was collected in the survey. The principal investigator's institutional Qualtrics account was used to prepare and distribute the survey. Categorical variables were summarized using frequency and percentage. Continuous variables were summarized using mean $\pm \mathrm{SD}$, range, and IQR. Bar plots and pie charts were used to depict the distribution of participants responding to the survey.

\section{Results}

The data set included 74 responders, of which 66 answered, "I agree to take the survey" and completed the survey. Six duplicate records were excluded and the final number of unique records was 60 . Among these, $70 \%(n=39)$ were from an academic setting, $12 \%(n=7)$ from the community, $11 \%(n=6)$ from private practice, and $7 \%(n=4)$ others. The distribution by continents was $65 \%(n=34)$ from North America, followed by $21 \%(n=11)$ from Europe, $8 \%(n=4)$ from South America, 4\% $(n=2)$ from Asia, and 2\% $(n=1)$ from Australia. Within North America, the distribution of respondents according to region included $22.6 \%(n=7)$ each from Canada, US-Northeast and US-South, $16.1 \%(n=5)$ each from US-West and Mid-west (3 respondents did not choose a state) (Fig. 1).

Among the 60 participants, 55\% $(n=33)$ used fusion biopsy in their institution. Among these, $73 \%(n=24)$ and $24 \%(n=8)$ of fusion biopsies were performed by Urology and Diagnostic Radiology, respectively. 64\% $(n=21)$ of the biopsies were transrectal, $3 \%(n=1)$ were transperineal, and

\section{LOCATIONS OF PRACTICE CONTINENTS OF PRACTICE}

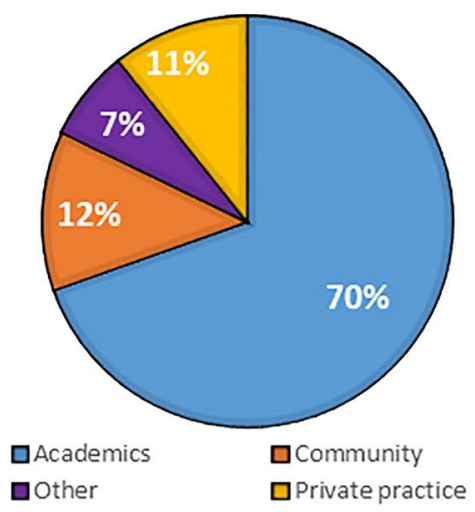

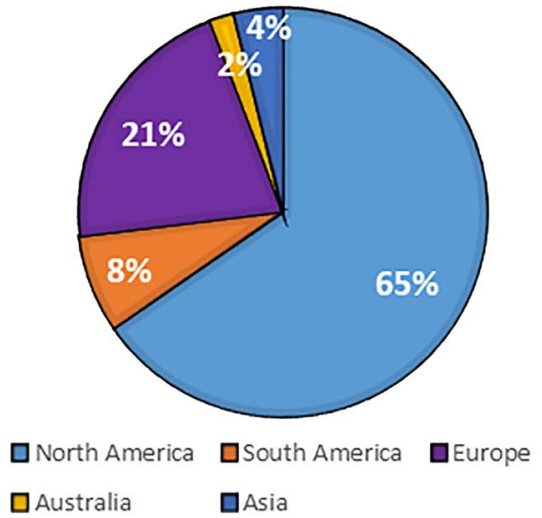

\section{NORTH AMERICA DISTRIBUTION}

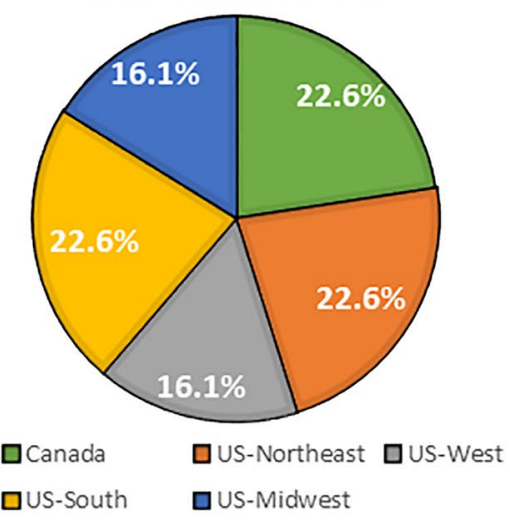

Fig. 1 Pie chart depicting the locations, continents, and North America distribution of the survey participants 
$30 \%(n=10)$ were both. Also, among these, $45 \%(n=15)$ of the fusion biopsies were performed in the hospitals, 39\% $(n=13)$ were performed in outpatient clinics, and 15\% $(n=5)$ were performed in both settings.

\section{Prostate MRI and biopsy case volumes}

Among all participants, the median (range) number of prostate MRI scans was $20(0,135)$ per week before the COVID19 pandemic vs. $10(0,30)$ during the lockdown period; the median (range) number of prostate biopsies was $4.5(0,60)$ per week before the COVID-19 pandemic vs. $0(0,12)$ during the lockdown period. $70 \%$ of the participants responded that the lockdown had finished at the time of this survey (July-August 2020). Among these, the median (range) number of prostate MRI was $15(0,125)$, and the median (range) number of prostate biopsies was $10(0,30)$ after lockdown (Table 1).

\section{MRI protocol and patient preparation}

Eight different combinations of the protocol based on magnet strength, use of contrast, and endorectal coil were provided (Question 10 of the questionnaire). The most commonly used protocol $(28.3 \%, n=17)$ was "mpMRI without an endorectal coil at $3 \mathrm{~T}$ ", followed by "mpMRI without an endorectal coil at 1.5 T" $(11.7 \%, n=7) .23 \%(n=14)$ of the participants answered that more than one MRI protocol was used. Among the 60 participants, $30 \%(n=18)$ responded that they used bowel preparation routinely prior to prostate MRI and $11 \%(n=2)$ stopped bowel preparation due to the pandemic. 30\% $(n=18)$ responded that they routinely use anti-spasmolytic and none of them stopped anti-spasmolytic due to the pandemic.

\section{Changes in workflow within radiology and other departments}

$68 \%(n=41)$ of survey participants reported that other clinical departments, particularly Urology, GU Medical Oncology, and Radiation Oncology canceled or limited their clinics during the lockdown, and $47 \%(n=28)$ reported that their department faced staff disruptions. $30 \%(n=18)$ of the prostate MRI interpretations were performed at hospital/outpatient imaging, 17\% $(n=10)$ remotely from home, and 22\% $(n=13)$ were performed both ways. In regard to safety precautions, $60 \%(n=36)$ answered that precautions/changes were implemented in the MRI/Biopsy suites, and 65\% $(n=39)$ reported that technologist/nursing staff received COVID-19 precautions training.

\section{COVID-19 test positivity and regulatory COVID-19 safety protocols}

$7 \%(n=4)$ of survey participants responded that MRI staff members tested positive for COVID-19 and 5\% $(n=3)$ responded that 'patients' scanned/biopsied tested positive for COVID-19. In most places, 62\% $(n=37)$ required that patients and staff wear masks at all times. Patients were subjected to temperature checks in $45 \%(n=27)$, routine COVID-19 testing in $25 \%(n=15)$ and a 14 -day period of self-quarantine after COVID-19 test positivity in 13\% $(n=8)$ of the institutions. Overall, $50 \%$ of the participants responded that two or more COVID-19 protocols were implemented at their workplace (Table 2).

\section{Impact of COVID-19 on prostate MRI/biopsy research}

COVID-19 pandemic had a negative impact on prostate MRI and biopsy research in 50\% $(n=30)$ and 47\% $(n=28)$ of the participants respectively. For the last question anticipating the duration of the COVID-19 pandemic effect on the MRI and biopsy schedules, the answers varied greatly; $20 \%(n=12)$ answered $1-3$ months, $18 \%(n=11)$ answered 4-6 months, $10 \%(n=6)$ answered 7-9 months, and 20\% $(n=12)$ answered $10-12$ months.

The distribution of the percentage of participants answering Questions 10-19 and Questions 20-30 of the questionnaire is summarized in Figs. 2 and 3 respectively.
Table 1 Summary of number of studies performed per week

\begin{tabular}{llcll}
\hline Questions & $N$ & Mean \pm SD & Median (Range) & IQR \\
\hline Prostate MRI before COVID-19 & 41 & $26 \pm 26$ & $20(0,135)$ & $(10,30)$ \\
Prostate MRI during lockdown & 32 & $11.6 \pm 8.2$ & $10(0,30)$ & $(5.5,15)$ \\
Prostate biopsies before COVID-19 & 40 & $7.9 \pm 11.7$ & $4.5(0,60)$ & $(0.1,10)$ \\
Prostate biopsies during lockdown & 32 & $2.3 \pm 3.3$ & $0(0,12)$ & $(0,5)$ \\
Prostate MRI after lockdown & 27 & $21.3 \pm 25.3$ & $15(0,125)$ & $(4,28)$ \\
Prostate biopsies after lockdown & 23 & $9.6 \pm 8$ & $10(0,30)$ & $(3,14)$ \\
\hline
\end{tabular}


Table 2 COVID-19 protocols in the Department

\begin{tabular}{|c|c|c|c|c|c|}
\hline $\begin{array}{l}\text { Patients and staff wear } \\
\text { masks at all times }\end{array}$ & $\begin{array}{l}\text { Patients are subjected to } \\
\text { temperature checks }\end{array}$ & $\begin{array}{l}\text { Patients are routinely } \\
\text { tested for COVID-19 }\end{array}$ & $\begin{array}{l}\text { Patients confirm } 14 \text { days self-quaran- } \\
\text { tine after COVID-19 test positivity }\end{array}$ & Frequency & Percentage \\
\hline No answer & No answer & No answer & No answer & 22 & 37 \\
\hline No & No & Yes & No & 1 & 2 \\
\hline Yes & No & No & No & 7 & 12 \\
\hline Yes & No & No & Yes & 1 & 2 \\
\hline Yes & No & Yes & No & 2 & 3 \\
\hline Yes & Yes & No & No & 13 & 22 \\
\hline Yes & Yes & No & Yes & 2 & 3 \\
\hline Yes & Yes & Yes & No & 7 & 12 \\
\hline Yes & Yes & Yes & Yes & 5 & 8 \\
\hline
\end{tabular}

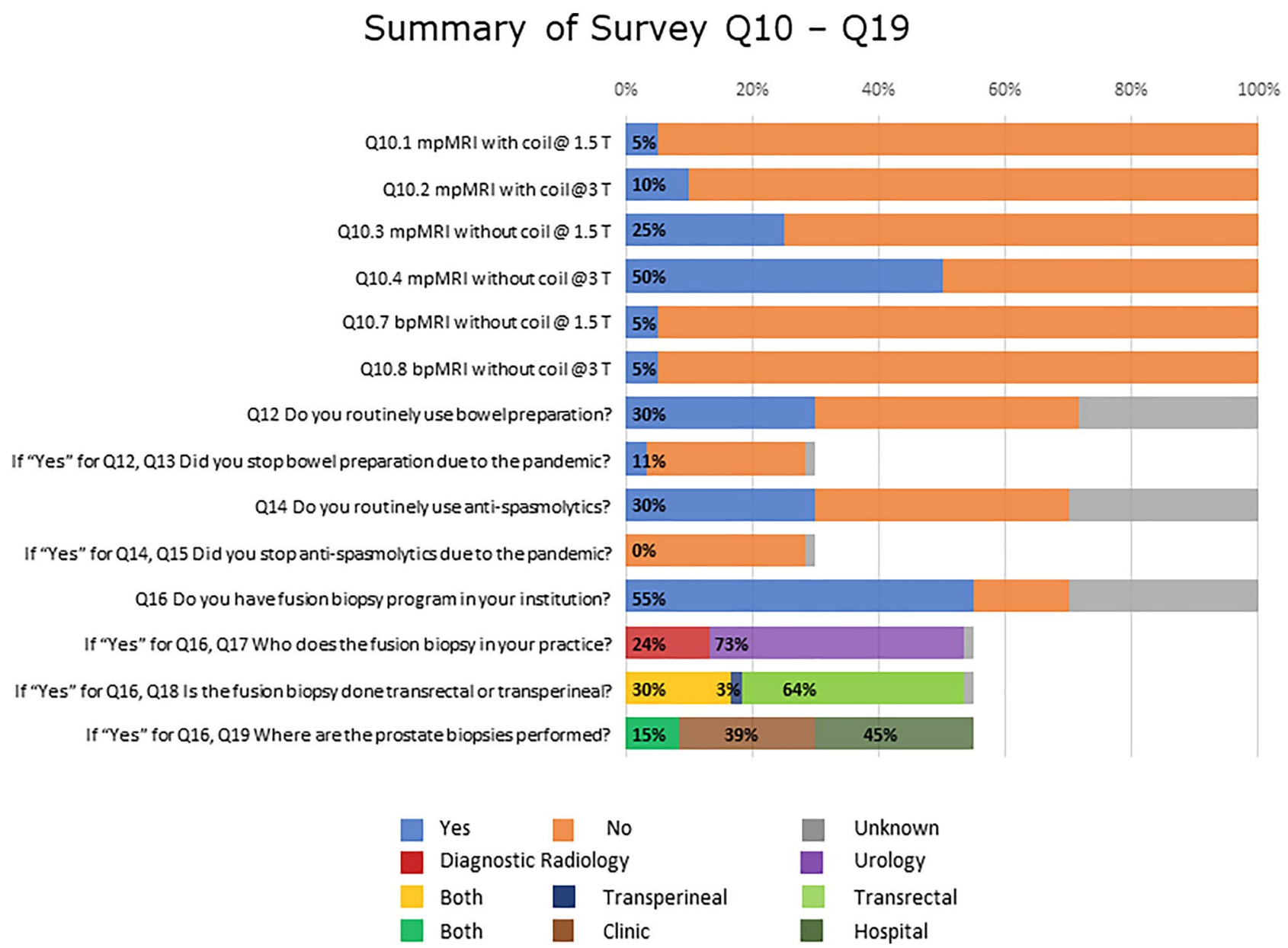

Fig. 2 Bar graph depicting the percentage of survey participants responding to Questions 10-19

\section{Discussion}

The COVID-19 pandemic has caused significant disruptions in the health care systems throughout the world. In an attempt to flatten the curve, there were cancellations of the non-emergent imaging procedures, outpatient clinics, and surgeries. Most of these changes were implemented to control the surge of new cases and preserve resources to treat COVID-19 positive cases. While some of the steps were necessary to achieve this goal and direct the health care providers' attention to acute and critically ill patients, it 


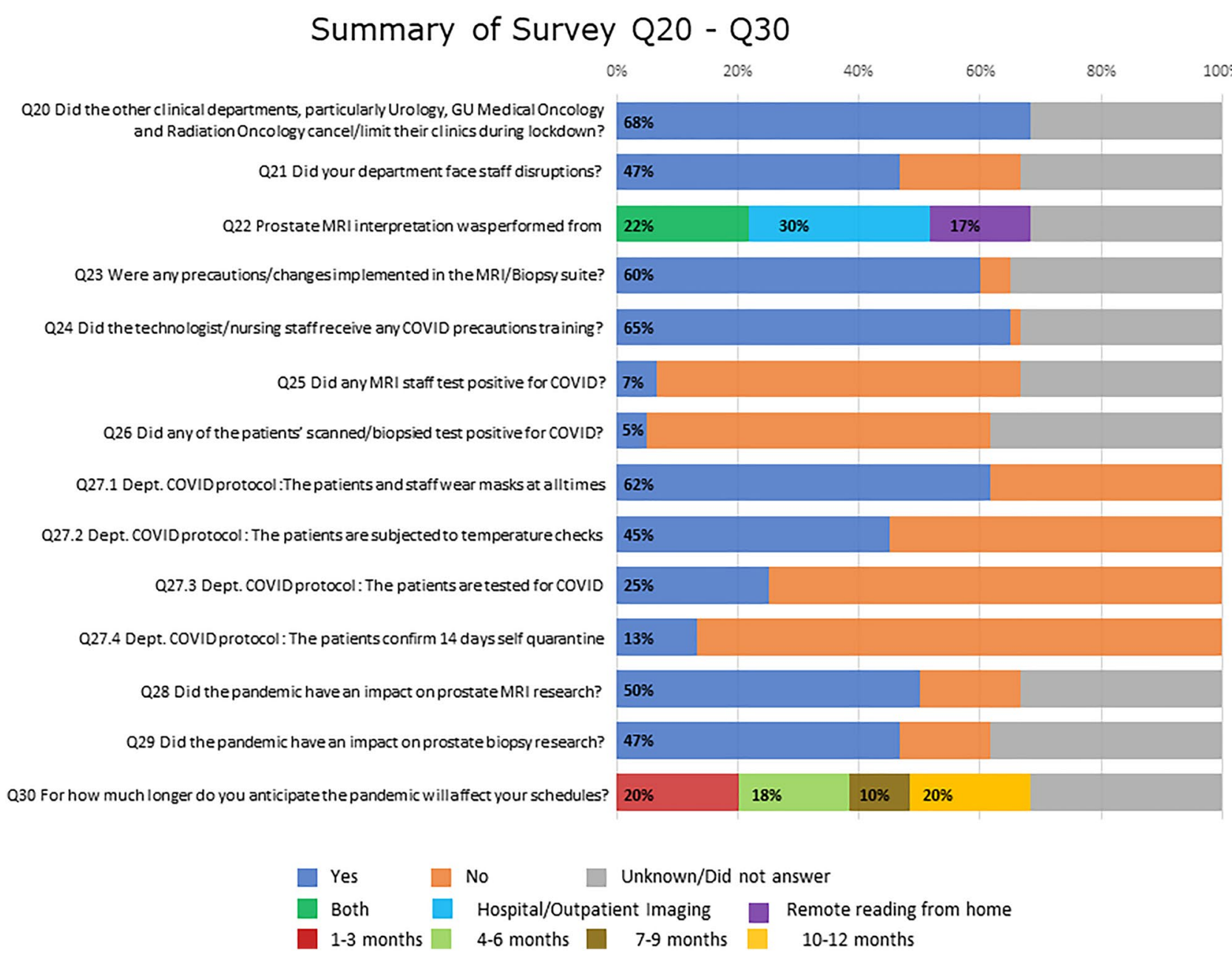

Fig. 3 Bar graph depicting the percentage of survey participants responding to Questions 20-30

has also led to collateral damages, including delayed prostate cancer diagnosis and potentially long-term financial implications. The online survey ran among world-wide radiology departments has enabled us to learn about the impact of the COVID-19 pandemic on the operations of prostate MRI studies and biopsies. The survey included representation from 5 continents, with $65 \%$ from North America. $70 \%$ of the survey respondents were from academic institutions.

Many radiology departments have witnessed a significant decrease in imaging volumes, particularly in the high surge areas [9]. As expected, the case volumes of prostate MRI and biopsies had decreased during the lockdown, with the case numbers almost catching up after the lockdown ended. Of the $30 \%$ participant radiologists who used bowel preparation routinely in their patients, $11 \%$ stopped it due to the pandemic. This could potentially impact prostate MRI quality in a negative way with suboptimal imaging results and misdiagnosis $[10,11]$. Additionally, other clinical departments which are crucial in referring patients for prostate
MRI and biopsies, including Urology, GU Medical Oncology, and Radiation Oncology canceled or limited their clinics during the lockdown in $68 \%$ of the centers, and in the short term, this would likely result in significant case backlogs, and at mid-term, delays in diagnosis and management can be expected.

One other aspect of the challenges is staff disruptions, which were noted in $47 \%$ of the radiology departments. The pandemic has forced radiology departments to change from a hospital-based setting to a home setting with home workstations, enabling the radiologists to practice from home [12, 13]. In the current survey, the respondents reported a combination of working from both the hospital and home setting. Additionally, amongst the departmental COVID-19 safety protocols, $62 \%$ enforced the mask policy for patients and staff at all times. Overall, $50 \%$ of the participants responded that two or more COVID-19 safety protocols were implemented at their workplace. As a possible result of these safety measures implemented in radiology clinics, only less than $10 \%$ of the respondents reported COVID-19 positive cases in the MRI 
staff members and patients who underwent MRI scans, biopsies. Finally, the impact of COVID-19 was seen not only on clinical operations but also on research efforts, with approximately half of the survey participants responding that there has been an impact on prostate MRI and biopsy research. In some institutions, a few internal funding mechanisms were halted along with closure of research facilities. Scarcity of resources for research can not only cause a financial impact but also lead to delays in innovation.

The survey was conducted in the months of mid-July to August when there was an improvement in the number of new cases. 70\% reported that the lockdown had ended, and we were able to document the impact of the initial lockdown process in the earlier months of the COVID-19 pandemic. At the time of submission of this manuscript, a few states within the United States and a few European countries were subjected to a second lockdown, and this would further the impact shown in this study.

Guitron et al. detailed the development of three complementary recovery models for radiology departments to plan and recover from the unpredictable impact of the pandemic [14]. A long-term volume model, estimating a swift, gradual, or muted recovery of imaging volumes; a short-term volume model predicting recovery volumes on a supply and demand basis and a next-wave model forecasting the impact of future surges on imaging volumes.

The limitations of the study include relatively low response rates from both individual email contacts and social media. The majority of the survey participants were academic physicians, and thus the results predominantly reflect the clinical operations in an academic setting but not the community as much. The survey was administered during the months of July and August 2020, and the results cannot be generalized with the changing surges of the COVID-19 pandemic and different levels of severity and coping mechanisms in the respondent institutions.

In conclusion, COVID-19 pandemic has significantly impacted many health care systems. As the pandemic continues with an increase in the number of new cases, the negative impact of the pandemic will continue with expected collateral damages, including prostate MRI and biopsy practices. The oncologic outcomes of pandemic related disruptions are currently unknown, and future studies will be needed to explore them. But hopefully, with the wider availability of the vaccine, continued safety precautions, and innovations in radiology operations, we can return to usual diagnostic volumes.

\section{Appendix: Survey questionnaire}

\begin{tabular}{|c|c|}
\hline Q1 & Do you agree to take the survey? \\
\hline Q2 & $\begin{array}{l}\text { Which one of the following best } \\
\text { describes your practice? } \\
\text { a. Academics } \\
\text { b. Community } \\
\text { c. Private practice } \\
\text { d. Other }\end{array}$ \\
\hline Q3 & $\begin{array}{l}\text { In which country do you currently } \\
\text { reside? }\end{array}$ \\
\hline Q4 & $\begin{array}{l}\text { In which state do you currently } \\
\text { reside? }\end{array}$ \\
\hline Q5 & Please enter the province/state \\
\hline Q6 & $\begin{array}{c}\text { When did the lockdown start for } \\
\text { your location }(\mathrm{mm} / \mathrm{dd} / \mathrm{yyyy}) ?\end{array}$ \\
\hline Q7 & Is the lockdown finished? Yes/No \\
\hline Q8 & $\begin{array}{l}\text { How many studies were done per } \\
\text { week before the COVID-19 situ- } \\
\text { ation and during lockdown? } \\
\text { a. Prostate MRI } \\
\text { b. Prostate biopsies }\end{array}$ \\
\hline Q9 & $\begin{array}{l}\text { Approximately how many studies } \\
\text { are being done now per week } \\
\text { after the lockdown? } \\
\text { a. Prostate MRI } \\
\text { b. Prostate biopsies }\end{array}$ \\
\hline Q10 & $\begin{array}{l}\text { What is your current MRI proto- } \\
\text { col? } \\
\text { a. mpMRI with an endorectal coil } \\
\text { @ } 1.5 \mathrm{~T} \\
\text { b. mpMRI with an endorectal coil } \\
\text { @ } 3 \mathrm{~T} \\
\text { c. mpMRI without an endorectal } \\
\text { coil @ } 1.5 \mathrm{~T} \\
\text { d. mpMRI without an endorectal } \\
\text { coil @ } 3 \mathrm{~T} \\
\text { e. bpMRI with an endorectal coil } \\
\text { @ } 1.5 \mathrm{~T} \\
\text { f. bpMRI with an endorectal coil } \\
\text { @ } 3 \mathrm{~T} \\
\text { g. bpMRI without an endorectal } \\
\text { coil @ } 1.5 \mathrm{~T} \\
\text { h. bpMRI without an endorectal } \\
\text { coil @ } 3 \mathrm{~T}\end{array}$ \\
\hline Q11 & $\begin{array}{l}\text { Did you stop using the coil due to } \\
\text { the pandemic? Yes/No }\end{array}$ \\
\hline Q12 & $\begin{array}{l}\text { Do you routinely use bowel prepa- } \\
\text { ration? Yes/No }\end{array}$ \\
\hline Q13 & $\begin{array}{c}\text { Did you stop bowel preparation } \\
\text { due to the pandemic? Yes/No }\end{array}$ \\
\hline Q14 & $\begin{array}{l}\text { Do you routinely use anti-spasmo- } \\
\text { lytics? Yes/No }\end{array}$ \\
\hline Q15 & $\begin{array}{l}\text { Did you stop anti-spasmolytics } \\
\text { due to the pandemic? Yes/No }\end{array}$ \\
\hline Q16 & $\begin{array}{l}\text { Do you have fusion biopsy pro- } \\
\text { gram in your institution? Yes/No }\end{array}$ \\
\hline
\end{tabular}




\begin{tabular}{|c|c|}
\hline$\overline{\mathrm{Q} 17}$ & $\begin{array}{l}\text { Who does the fusion biopsy in } \\
\text { your practice? } \\
\text { a. Diagnostic Radiology } \\
\text { b. Interventional Radiology } \\
\text { c. Urology }\end{array}$ \\
\hline Q18 & $\begin{array}{l}\text { Is the fusion biopsy done transrec- } \\
\text { tal or transperineal or both? }\end{array}$ \\
\hline Q19 & $\begin{array}{l}\text { Where are the prostate biopsies } \\
\text { performed? } \\
\text { a. Clinic } \\
\text { b. Operating room } \\
\text { c. Both }\end{array}$ \\
\hline Q20 & $\begin{array}{l}\text { Did the other clinical depart- } \\
\text { ments, particularly Urology, GU } \\
\text { Medical Oncology and Radiation } \\
\text { Oncology cancel/limit their clin- } \\
\text { ics during lockdown? Yes/No }\end{array}$ \\
\hline Q21 & $\begin{array}{l}\text { Did your department face staff } \\
\text { disruptions? Yes/No }\end{array}$ \\
\hline Q22 & $\begin{array}{l}\text { Prostate MRI interpretation was } \\
\text { performed from } \\
\text { a. Hospital/Outpatient setting } \\
\text { b. Home } \\
\text { c. Both }\end{array}$ \\
\hline Q23 & $\begin{array}{l}\text { Were any precautions/changes } \\
\text { implemented in the MRI/Biopsy } \\
\text { suite? Yes/No }\end{array}$ \\
\hline Q24 & $\begin{array}{l}\text { Did the technologist/nursing staff } \\
\text { receive any COVID-19 precau- } \\
\text { tions training? Yes/No }\end{array}$ \\
\hline Q25 & $\begin{array}{l}\text { Did any MRI staff test positive for } \\
\text { COVID-19? Yes/No }\end{array}$ \\
\hline Q26 & $\begin{array}{l}\text { Did any of the patients' scanned/ } \\
\text { biopsied test positive for } \\
\text { COVID-19? }\end{array}$ \\
\hline Q27 & $\begin{array}{l}\text { What is your Dept. COVID-19 } \\
\text { protocol? } \\
\text { a. The patients and staff wear } \\
\text { masks at all times } \\
\text { b. The patients are subjected to } \\
\text { temperature checks } \\
\text { c. The patients are tested for } \\
\text { COVID } \\
\text { d. The patients confirm } 14 \text { days } \\
\text { self-quarantine }\end{array}$ \\
\hline Q28 & $\begin{array}{l}\text { Did the pandemic have an impact } \\
\text { on prostate MRI research? Yes/ } \\
\text { No }\end{array}$ \\
\hline Q29 & $\begin{array}{l}\text { Did the pandemic have an impact } \\
\text { on prostate biopsy research? } \\
\text { Yes/No }\end{array}$ \\
\hline Q30 & $\begin{array}{l}\text { For how much longer do you } \\
\text { anticipate the pandemic will } \\
\text { affect your schedules? } \\
\text { a. } 1-3 \text { months } \\
\text { b. } 4-6 \text { months } \\
\text { c. } 7-9 \text { months } \\
\text { d. } 10-12 \text { months }\end{array}$ \\
\hline
\end{tabular}

Acknowledgments We thank the SAR Prostate Cancer DFP members and radiologists who participated in the survey. We would also like to acknowledge Ms. Paula Iaeger PhD (Manager of the Office of Institutional Research, Academic Analytics and Technology, The University of Texas MD Anderson Cancer Center, Houston).

Author contributions Conceptualization: DSSS, ACW, SDC, BT. Data curation: DSSS. Formal Analysis: DSSS, XW, HH. Investigation: DSSS, ACW, SDC, BT. Methodology: DSSS, TKB, SA, ACW, SDC, BT. Project administration: DSSS, TKB. Resources: DSSS, ACW, SDC, BT. Software: DSSS, XW, HH. Supervision: DSSS, TKB, ACW, SDC, BT. Validation: DSSS, BT. Visualization: DSSS, ACW, SDC, BT. Writing - DSSS, XW, BT. Writing - review \& editing: DSSS, XW, TKB, HH, SA, ACW, SDC, BT. DSSS: Devaki Shilpa Sudha Surasi; XW: Xuemei Wang, TKB: Tharakeswara K. Bathala, HH: Hyunsoo Hwang; SA: Sandeep Arora, ACW: Antonio C. Westphalen, SDC: Silvia D. Chang, BT: Baris Turkbey.

Funding No funding was received to assist with the preparation of this manuscript.

Data availability All data and materials support the published claims and comply with field standards.

\section{Declarations}

Conflict of interest The authors have no conflicts of interest to declare that are relevant to the content of this article.

Ethical approval This prospective survey-based study received institutional review board approval from the research ethics committee at The University of Texas MD Anderson Cancer Center, Houston, United States.

Informed consent Answering "Yes" to the first survey question served as a consent to participate in the study. The authors affirm that human research participants provided informed consent for publication.

\section{References}

1. Helmy YA, Fawzy M, Elaswad A, Sobieh A, Kenney SP, Shehata AA (2020) The COVID-19 Pandemic: A Comprehensive Review of Taxonomy, Genetics, Epidemiology, Diagnosis, Treatment, and Control. Journal of clinical medicine 9 (4). https://doi.org/ $10.3390 / \mathrm{jcm} 9041225$

2. COVID-19 Dashboard by the Center for Systems Science and Engineering (CSSE) at Johns Hopkins University (JHU) (2020).

3. Masroor S (2020) Collateral damage of COVID-19 pandemic: Delayed medical care. Journal of cardiac surgery 35 (6):13451347. https://doi.org/10.1111/jocs. 14638

4. Karam C, Badiani S, Berney CR (2020) COVID-19 collateral damage: delayed presentation of a perforated rectal cancer presenting as Fournier's gangrene. ANZ journal of surgery. https:// doi.org/10.1111/ans.16104

5. Haut ER, Leeds I, Livingston DH (2020) The Effect on Trauma Care Secondary to the COVID-19 Pandemic: Collateral Damage from Diversion of Resources. Annals of surgery. https://doi.org/ 10.1097/sla.0000000000004105

6. Montaner J, Barragán-Prieto A, Pérez-Sánchez S, Escudero-Martínez I, Moniche F, Sánchez-Miura JA, Ruiz-Bayo L, González A (2020) Break in the Stroke Chain of Survival Due to COVID-19. 
Stroke:Strokeaha120030106. https://doi.org/10.1161/strokeaha. 120.030106

7. Seely JM, Scaranelo AM, Yong-Hing C, Appavoo S, Flegg C, Kulkarni S, Kornecki A, Wadden N, Loisel Y, Schofield S, Leslie S, Gordon P (2020) COVID-19: Safe Guidelines for Breast Imaging During the Pandemic. Canadian Association of Radiologists journal $=$ Journal l'Association canadienne des radiologistes:846537120928864. https://doi.org/10.1177/0846537120 928864

8. Tashkandi E, Zeeneldin A, AlAbdulwahab A, Elemam O, Elsamany S, Jastaniah W, Abdullah S, Alfayez M, Jazieh AR, Al-Shamsi HO (2020) Virtual Management of Patients With Cancer During the COVID-19 Pandemic: Web-Based Questionnaire Study. Journal of medical Internet research 22 (6):e19691. https:// doi.org/10.2196/19691

9. Norbash AM, Moore AV, Jr., Recht MP, Brink JA, Hess CP, Won JJ, Jain S, Sun X, Brown M, Enzmann D (2020) Early-Stage Radiology Volume Effects and Considerations with the Coronavirus Disease 2019 (COVID-19) Pandemic: Adaptations, Risks, and Lessons Learned. Journal of the American College of Radiology : JACR 17 (9):1086-1095. https://doi.org/10.1016/j.jacr.2020.07. 001

10. Caglic I, Hansen NL, Slough RA, Patterson AJ, Barrett T (2017) Evaluating the effect of rectal distension on prostate multiparametric MRI image quality. Eur J Radiol 90:174-180. https://doi. org/10.1016/j.ejrad.2017.02.029
11. Purysko AS, Mielke N, Bullen J, Nachand D, Rizk A, Stevens E, Ward RD, Klein EA, Rosenkrantz AB, Ream JM (2020) Influence of Enema and Dietary Restrictions on Prostate MR Image Quality: A Multireader Study. Acad Radiol. https://doi.org/10.1016/j.acra. 2020.10.019

12. Sammer MBK, Sher AC, Huisman T, Seghers VJ (2020) Response to the COVID-19 Pandemic: Practical Guide to Rapidly Deploying Home Workstations to Guarantee Radiology Services During Quarantine, Social Distancing, and Stay Home Orders. AJR American journal of roentgenology 215 (6):1417-1420. https:// doi.org/10.2214/ajr.20.23297

13. Tridandapani S, Holl G, Canon CL (2020) Rapid Deployment of Home PACS Workstations to Enable Social Distancing in the Coronavirus Disease (COVID-19) Era. AJR American journal of roentgenology 215 (6):1351-1353. https://doi.org/10.2214/ajr.20. 23495

14. Guitron S, Pianykh OS, Succi MD, Lang M, Brink J (2020) COVID-19: Recovery Models for Radiology Departments. Journal of the American College of Radiology : JACR 17 (11):14601468. https://doi.org/10.1016/j.jacr.2020.09.020

Publisher's Note Springer Nature remains neutral with regard to jurisdictional claims in published maps and institutional affiliations. 